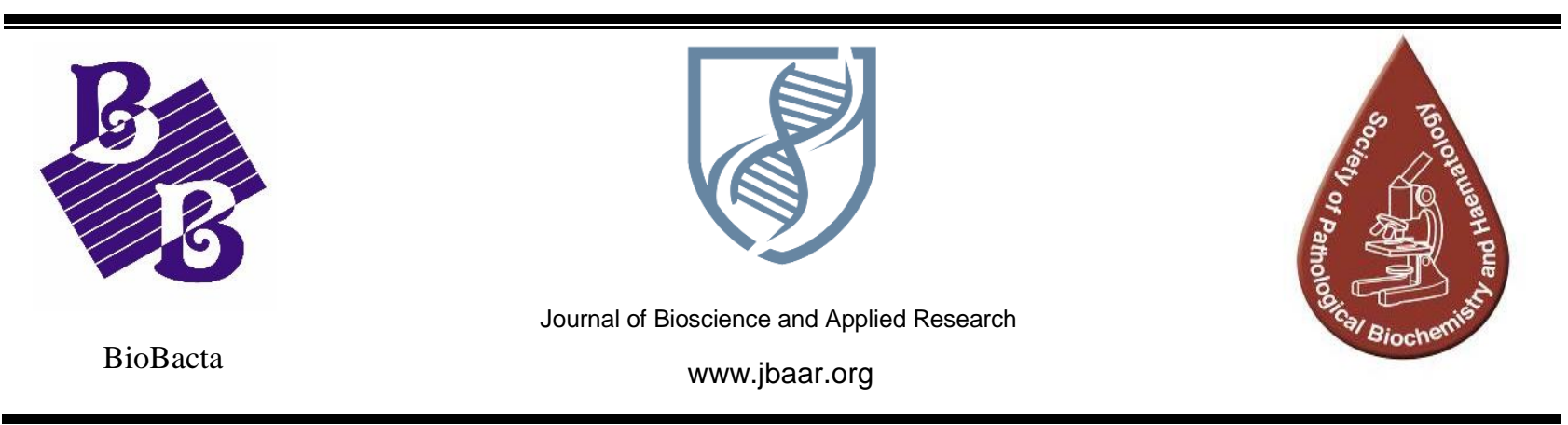

\title{
CD47 Expression in Egyptian Patients with Acute Myeloid Leukemia
}

\section{${ }^{1}$ Samar Saber, ${ }^{1}$ Samir A. El-Masry, ${ }^{2}$ Salah Aref}

${ }^{1}$ Molecular Biology Department, Genetic Engineering and Biotechnology institute, Sadat University, Egypt

${ }^{2}$ Clinical Pathology Department, Faculty of Medicine, Mansoura University, Egypt

Received: October 20, 2019; Accepted: November 27, 2019

DOI: 10.21608/jbaar.2019.114537

\begin{abstract}
Background and objective: Acute myeloid leukemia (AML) is a genetically heterogeneous clonal disease defined by the proliferation and accumulation in the bone marrow and blood of immature hematopoietic cells. (CD47) acts as an important negative indicator for phagocytic cells and is reported to have been overexpressed in multiple human tumour cells. Expression of CD47 on blast cells relation to patient's characteristics and outcome with leukemia and correlates inversely with survival in AML patients. This study aimed to evaluate the CD47 gene expression in Egyptian AML patients and its role in the pathogenesis of the disease and as a prognostic marker related to overall survival (OS). Methods: This study was conducted on 55 patients with AML and 21 healthy individuals as a control group to evaluate the CD47 gene expression using flow-cytometry in the bone marrow and peripheral blood samples.

Results: Statistically significant difference $(\mathrm{P}<0.0001)$ between two groups AML patients and control group in Hemoglobin $(\mathrm{g} / \mathrm{dL})$, WBCs $\left(10^{3} / \mu \mathrm{L}\right)$ and PLTs count $\left(10^{3} / \mu \mathrm{L}\right)$. Our results on the frequency of CD47 expression differ significantly among FAB subtype in AML patients. There was an inverse correlation between CD47 expression and general survival, with enhanced expression also connected with worse general survival $(\mathrm{P}<0.0001)$. Conclusion: Our results obtained by this study provide additional evidence of the role of the CD47 gene as a predictive factor impact on prognosis and over survival (OS).
\end{abstract}

Keywords: AML; CD47; Marker; prognosis 


\section{Introduction}

Acute myeloid leukemia (AML) is a malignant neoplasm of immature myeloid cells originating from the bone marrow (BM), with variable differentiation. AML characterized by the clonal expansion of peripheral blood, bone marrow, and/or other tissues of myeloid blasts (Jaffe et al., 2016). It is the most common form of adult acute leukemia, and accounts for the largest number of annual leukemia deaths in the U.S. An estimated 21,450 people will be diagnosed with AML in 2019, and 10,920 patients will die of the disease (Siegel et al., 2019). In Egypt, leukemia comprises $10 \%$ of all malignancies, with AML representing 16.9\% (Egypt cancer registry, 2011). Patients with acute myeloid leukemia most often experience irregular laboratory findings including leukocytosis, anemia, and thrombocytopenia. AML's diagnostic work involves combining experience, clinical presentation, and laboratory results with pathologist-led studies. Such studies include morphological assessment of BM aspirate, BM biopsy, and $\mathrm{PB}$ smear, immunohistochemistry (IHC), flow cytometry (FC), cytogenetic tests, and molecular mutation analysis (Arber, 2019).

On their surface, leukocytes exhibit molecules that are critical to detect dangerous changes in the environment and to mediating cell adhesion and contact between cells both within the immune system and with stroma. Those include receptors, transporters, channels, proteins that bind to cells, and enzymes. The number of proteins expressed on the surface, also called the surfaceome, emphasized by the fact that an estimated $26 \%$ of human genes encode transmembrane proteins $(\sim 5,500)$ (Fagerberg et al., 2010). Workshops on human leukocyte differentiation antigen (HLDA) have culminated in the characterization and formal classification of over 400 surface molecules, known as CD molecules (Engel et al., 2015, Clark et al., 2016). CD47 is a trans-membrane glycoprotein that is commonly expressed in most human tissues and acts as a ligand for various receptors, including alpha (SIRP) signal regulatory protein. CD47-SIRP tagging on macrophages or dendritic cells results in phagocytosis inhibition by immunoreceptor tyrosine-based inhibition motive (ITIM)-mediated recruitment of protein-tyrosine phosphatases Src homology region 2 domain-containing phosphatase-1/2 (SHP-1/2) (Galli et al., 2015). CD47 expression is increased on AML leukemia stem cells (LSCs) relative to normal hematopoietic stem cells (HSCs), as calculated by flow cytometry (Jaiswal et al., 2009). CD47 expression upregulation is mainly a physiological mechanism: cyclophosphamide administration, the stimulating factor of granulocyte-colony (G-CSF) and lipopolysaccharide, Induce mobilization of HSCs, leading to a significantly elevated expression of CD47 on circulating HSCs in comparison with their counterpart's resident in the bone marrow (BM). This CD47 up-regulation probably protects mobilized HSC from subsequent phagocytosis mediated by macrophage (Jaiswal et al., 2009). In addition, CD47 has been shown to be of prognostic importance in AML (Jiang et al., 2013). The aim of the present study was to investigate the correlation between CD47 expression on bone marrow blasts and clinical outcomes using flow cytometry in Egyptian populations with acute myeloid leukemia.

\section{SUBJECTS AND METHODS}

\section{Study population and design}

This prospective cross-sectional study was conducted on Egyptian patients with leukemia in Mansoura University Hospital, Mansoura, Egypt work-ups from 2016 to 2018. This study was included 55 patients with newly diagnosed Acute Myeloid Leukemia, and 21 healthy individuals as a control group with matching age and sex were admitted to Mansoura University Hospital. Patients with Philadelphia-positive leukemia, infantile leukemia, mixed lineage leukemia, and Burkitt-type leukemia were included and the patients with hereditary or systemic disorders were excluded.

\section{Samples collection:}




\section{Blood samples:}

Collect blood aseptically by venipuncture 1,2 into a sterile blood collection tube with dipotassium ethylene diamine tetra-acetic acid (K2EDTA) vacutainer. Follow the instructions of the collection tube supplier for the required volume of blood to collect. Store blood until performing the complete blood cell counts (CBC), staining, and lysing at room temperature.

Bone marrow samples: Bone marrow aspiration was done under complete aseptic conditions at the time of diagnosis: a small part of aspirate was used for spreading smears to be examined by Leishman and MPO stains, $1 \mathrm{ml}$ was dispensed into a sterile tube containing K-EDTA to be used for the flowcytometry for immunophenotyping detection.

\section{Biochemical and haematological analyses} Complete blood count (CBC) and blood smear: $\mathrm{CBC}$ was determined using the electronic counter (CELL-DYN 3700, Abbott, Canda) to determine HB, HCT, erythrocytes, RBCs: mean corpuscle volume (MCV), mean corpuscle $\mathrm{HB}$ content in RBCS $(\mathrm{MCH})$. Peripheral blood smears preferred by finger-stick made for review with bone marrow. Two direct smears manually, adjusting for proper length and thickness.

\section{Flowcytometry assay for CD47:}

For CD47 analysis, expression was performed with an antihuman CD47 FITC (fluorescein isothiocyanate) antibody (clone B6H12.2, BD Pharmingen ${ }^{\mathrm{TM}}$ ), as following: add the appropriate volume of fluorochrome-conjugated monoclonal antibody to $100 \mu \mathrm{L}$ of fresh bone marrow samples in a 12 x 75-mm tube. Vortex gently and incubate 15 to 30 minutes in the dark at room temperature $\left(20^{\circ}\right.$ to $25^{\circ} \mathrm{C}$ ). Add $2 \mathrm{~mL}$ of $1 \mathrm{X}$ FACS Lysing Solution. Vortex gently and incubate for 10 minutes in the dark at room temperature. Centrifuge at 500 $\mathrm{x} g$ for 5 minutes. Remove the supernatant. Add 2 to $3 \mathrm{~mL}$ of wash buffer and centrifuge at $500 \mathrm{x}$ f for 5 minutes. Remove the supernatant. Add $0.5 \mathrm{~mL}$ of $1 \%$ paraformaldehyde solution and mix thoroughly. Store at $2^{\circ}$ to $8^{\circ} \mathrm{C}$ until analyzed. Analyze on a flow cytometer (FACSC into flow cytometer with Cell Quest software; Becton Dickinson) (Tabernero et al., 2001). Mix samples thoroughly before the acquisition. Refer to the appropriate package insert for storage restrictions prior to analysis.

\section{Ethical approval}

All investigations were performed in accordance with the Mansoura University Medical Research Ethics Clearance Committee guidelines, Mansoura University, Egypt. The local ethics committee approved the study protocol and Informed consent was got from all subjects.

\section{Statistical Analysis:}

Quantitative data were presented as a minimum, maximum, mean, median, and standard deviation (SD) values. Data showed a non-parametric distribution and so the Mann-Whitney U test was used for comparisons among groups. This test is the nonparametric alternative to Student's t-test. Qualitative data were presented as frequencies and percentages. Chi-square $\left(\mathrm{x}^{2}\right)$ test was used for studying the comparisons and associations between different qualitative variables. Spearman's correlation coefficient was used to determine significant correlations between the expression of CD47 and other different variables. Kaplan-Meier survival curve was constructed for survival analysis. The significance level was set at $\mathrm{P} \leq 0.05$. Statistical analysis was performed with IBM® SPSS ${ }^{\circledR}$ Statistics Version 24 for Microsoft Windows, SPSS Inc. and considered statistically significant at a two-sided $\mathrm{P}<0.05$.

\section{RESULTS}

\section{Baseline characteristics of included patients}

The present study was conducted on 55 patients with AML and 21 healthy individuals collected from the oncology center, Mansoura University Hospitals, Mansoura, Egypt. Out of 55 participants, $32(58.2 \%)$ were males and $23(41.8 \%)$ were females and out of 21 control, 10 (47.6\%) were males and 11 (52.4\%) were females. The mean age of patients was $45.8 \pm 15.1$ years standard deviation (SD) with the ranged from 19 to 71 years and 
control $39.9 \pm 12.8$ years standard deviation (SD) In the present study, the mean level of Hemoglobin with the range from 20 to 63 years. Sociodemographic and clinical data were summarized in Table 1.

Hematological parameters $(\mathrm{Hb})(\mathrm{g} / \mathrm{dL})$, the mean count of WBCs $(103 / \mu \mathrm{L})$ and the mean count of PLTs $(103 / \mu \mathrm{L})$ in both AML patients and healthy. There was a significant difference $(\mathrm{P}<0.0001)$ between the patients and healthy groups in Table 1.

Table 1: Characteristics of AML patients and healthy control groups

\begin{tabular}{|c|c|c|c|c|c|c|}
\hline Characteristics & Categories & \multicolumn{2}{|c|}{$\begin{array}{l}\text { Control } \\
(\mathrm{No}=21)\end{array}$} & \multicolumn{2}{|c|}{$\begin{array}{l}\text { AML patients } \\
\qquad(\mathrm{No}=55)\end{array}$} & $P$ value \\
\hline \multirow{3}{*}{ Gender } & Male & $\mathrm{N}$ & $\%$ & $\mathrm{~N}$ & $\%$ & \\
\hline & & 10 & $(47.6 \%)$ & 32 & $(58.2 \%)$ & \multirow{2}{*}{-} \\
\hline & Female & 11 & $(52.4 \%)$ & 23 & $(41.8 \%)$ & \\
\hline Age (years) & Mean \pm SD & \multicolumn{2}{|c|}{$39.9 \pm 12.8$} & \multicolumn{2}{|c|}{$45.8 \pm 15.1$} & $P>0.05$ \\
\hline \multirow[t]{2}{*}{ Hb (g/dl) } & Mean \pm SD & \multicolumn{2}{|c|}{$11.5 \pm 1.3$} & \multicolumn{2}{|c|}{$8.2 \pm 2.1$} & \multirow[t]{2}{*}{$P<0.0001$} \\
\hline & range & \multicolumn{2}{|c|}{$(9.7-13.8)$} & \multicolumn{2}{|c|}{$(3.8-16.2)$} & \\
\hline \multirow{2}{*}{$\begin{array}{l}\text { WBCs } \\
\times 103 / \mathrm{cmm}\end{array}$} & Mean \pm SD & \multicolumn{2}{|c|}{$6.2 \pm 1.5$} & \multicolumn{2}{|c|}{$56.9 \pm 16.3$} & \multirow{2}{*}{$P<0.0001$} \\
\hline & range & \multicolumn{2}{|c|}{$(4.3-9.7)$} & \multicolumn{2}{|c|}{$(8.4-280.0)$} & \\
\hline \multirow{2}{*}{$\begin{array}{l}\text { Platelets } \\
\text { x 103/cmm }\end{array}$} & Mean \pm SD & \multirow{2}{*}{\multicolumn{2}{|c|}{$\begin{array}{c}236.0 \pm 43.0 \\
(183.0-320.0)\end{array}$}} & \multirow{2}{*}{\multicolumn{2}{|c|}{$\begin{array}{c}42.8 \pm 18.3 \\
(55.0-161.0)\end{array}$}} & \multirow{2}{*}{$P<0.0001$} \\
\hline & range & & & & & \\
\hline \multirow[b]{2}{*}{ B.M. blasts (\%) } & Mean \pm SD & & & \multicolumn{2}{|c|}{$68.1 \pm 20.5$} & \\
\hline & range & & & \multicolumn{2}{|c|}{$(26.0-100.0)$} & \\
\hline \multirow{3}{*}{$\begin{array}{l}\text { FAB subtype } \\
\text { M1 (no. , \%) } \\
\text { M2 (no. , \%) }\end{array}$} & & \multirow{3}{*}{\multicolumn{2}{|c|}{ - }} & \multicolumn{2}{|c|}{$10(18.2 \%)$} & \multirow{6}{*}{ - } \\
\hline & & & & \multicolumn{2}{|c|}{$11(20.0 \%)$} & \\
\hline & & & & \multicolumn{2}{|c|}{$3(3.6 \%)$} & \\
\hline \multicolumn{2}{|l|}{ M3 (no. , \%) } & \multirow{2}{*}{\multicolumn{2}{|c|}{-}} & & 800 & \\
\hline M4 (no. , \%) & & & & \multicolumn{2}{|c|}{$20(36.4 \%)$} & \\
\hline M5 (no. , \%) & & \multicolumn{2}{|c|}{ - } & \multicolumn{2}{|c|}{$12(21.8 \%)$} & \\
\hline
\end{tabular}

AML: patients with Acute Myeloid Leukemia, SD: standard division, B.M.: bone marrow and FAB: French-American-British 


\section{Frequency of CD47 gene expression according to}

\section{FAB subtype in AML patients}

Our finding on CD47 gene expression in AML patients was significantly in form of FAB. Flowcytometric analysis of CD47 expression showed that the mean percentage of CD47 was increased with FAB type excretion, $38.6 \pm 39.5$ with M1, $51.1 \pm 34.9$ with M2, $60.2 \pm 51.9$ with M3 with M4, and 43.2 \pm 31.4 with M5 with M4; Table 2.

Table 2: Mean percentage of CD47 gene expression according to FAB type in AML patients

\begin{tabular}{|c|c|c|c|c|}
\hline FAB type & Mean \pm SD $(\%)$ & Minimum & Maximum & P value \\
\hline M1 & $38.6 \pm 39.5$ & 2.3 & 99.5 & \multirow{5}{*}{$\mathrm{P}<0.01$} \\
\hline M2 & $51.1 \pm 34.9$ & 3.1 & 97.0 & \\
\hline M3 & $60.2 \pm 51.9$ & 23.5 & 97.0 & \\
\hline M4 & $33.1 \pm 22.6$ & 8.4 & 86.8 & \\
\hline M5 & $43.2 \pm 31.4$ & 4.4 & 96.0 & \\
\hline
\end{tabular}

\section{Survival analyses}

Survival analyses were carried out using Kaplan Meier curve to examine the expression of CD47 with Over Survival (OS) as shown in Figure 1.

A
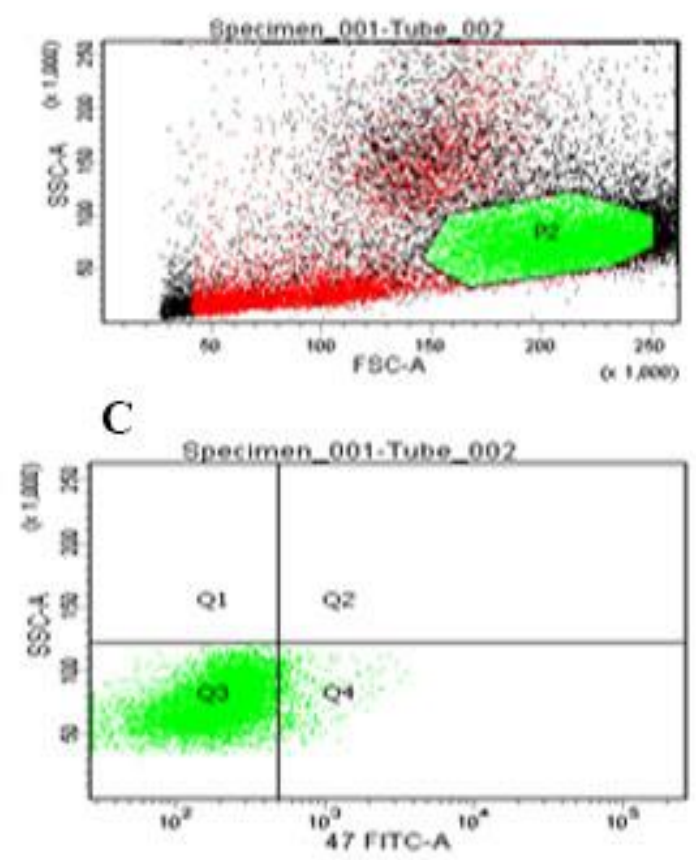

B

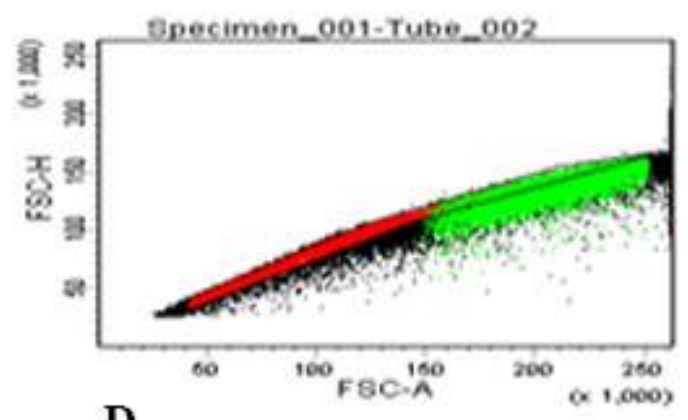

D

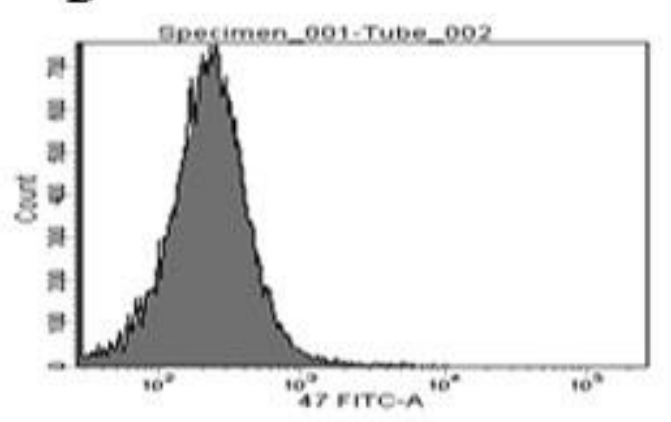

Fig. 1: showed a negative case of CD47 expression analysis (A) Gating strategy on forward and side scatter histogram, (B) single and double discretion histogram, and (C) auto negative control of cases, (D) MFI of CD47. 
Table 3: Frequency of outcome (\%) in AML patients

\begin{tabular}{|c|c|c|c|c|}
\hline & Outcome & Frequency & Percent & Total \\
\hline \multirow{3}{*}{$\begin{array}{c}\text { Induction of } \\
\text { Remission }(n=55)\end{array}$} & Complete Remission & 45 & $81.8 \%$ & \multirow{5}{*}{$\begin{array}{c}55 \\
(100 \%)\end{array}$} \\
\hline & Resistant & 6 & $10.9 \%$ & \\
\hline & Incomplete Remission & 4 & $7.3 \%$ & \\
\hline \multirow[t]{2}{*}{ Survival $(n=55)$} & Live & 35 & $63.6 \%$ & \\
\hline & Dead & 20 & $36.4 \%$ & \\
\hline
\end{tabular}

A

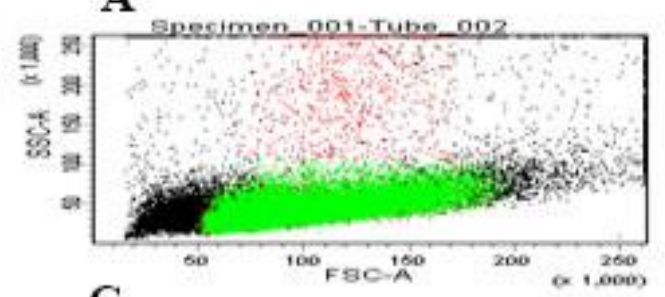

C

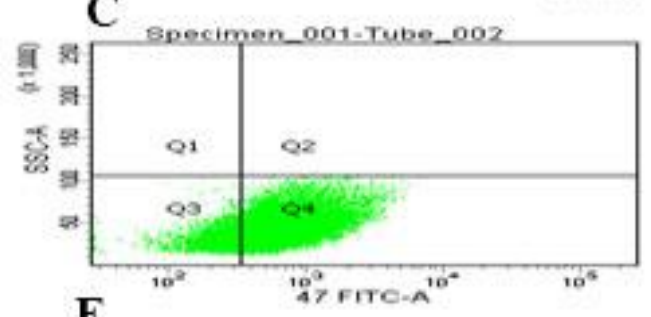

E

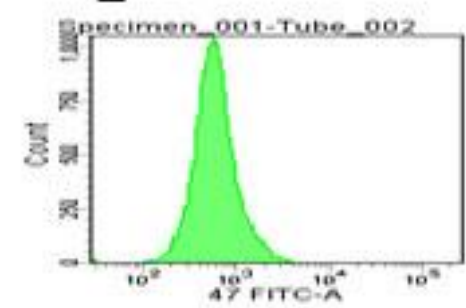

B

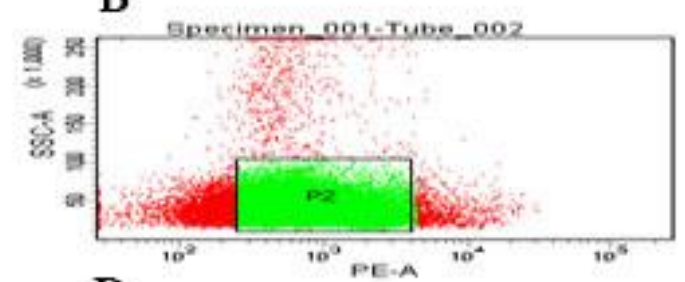

D

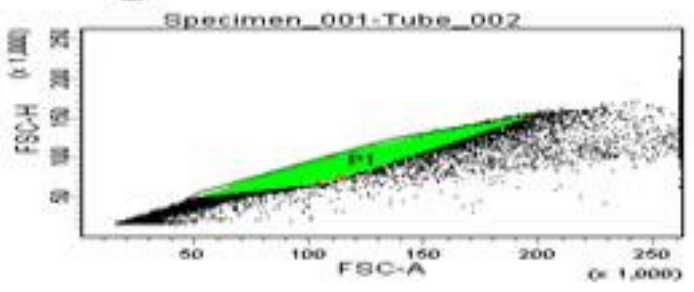

Fig. 2: showed a positive case of CD47 expression analysis. (A) Gating strategy on forward and side scatter histogram, (B) 
Fig. 3: Survival analysis of CD47 expression. The relation between OS (month) and CD47 expression level reported that high patients with CD47 expression had shorter overall survival as compared to those with low CD47 expression.

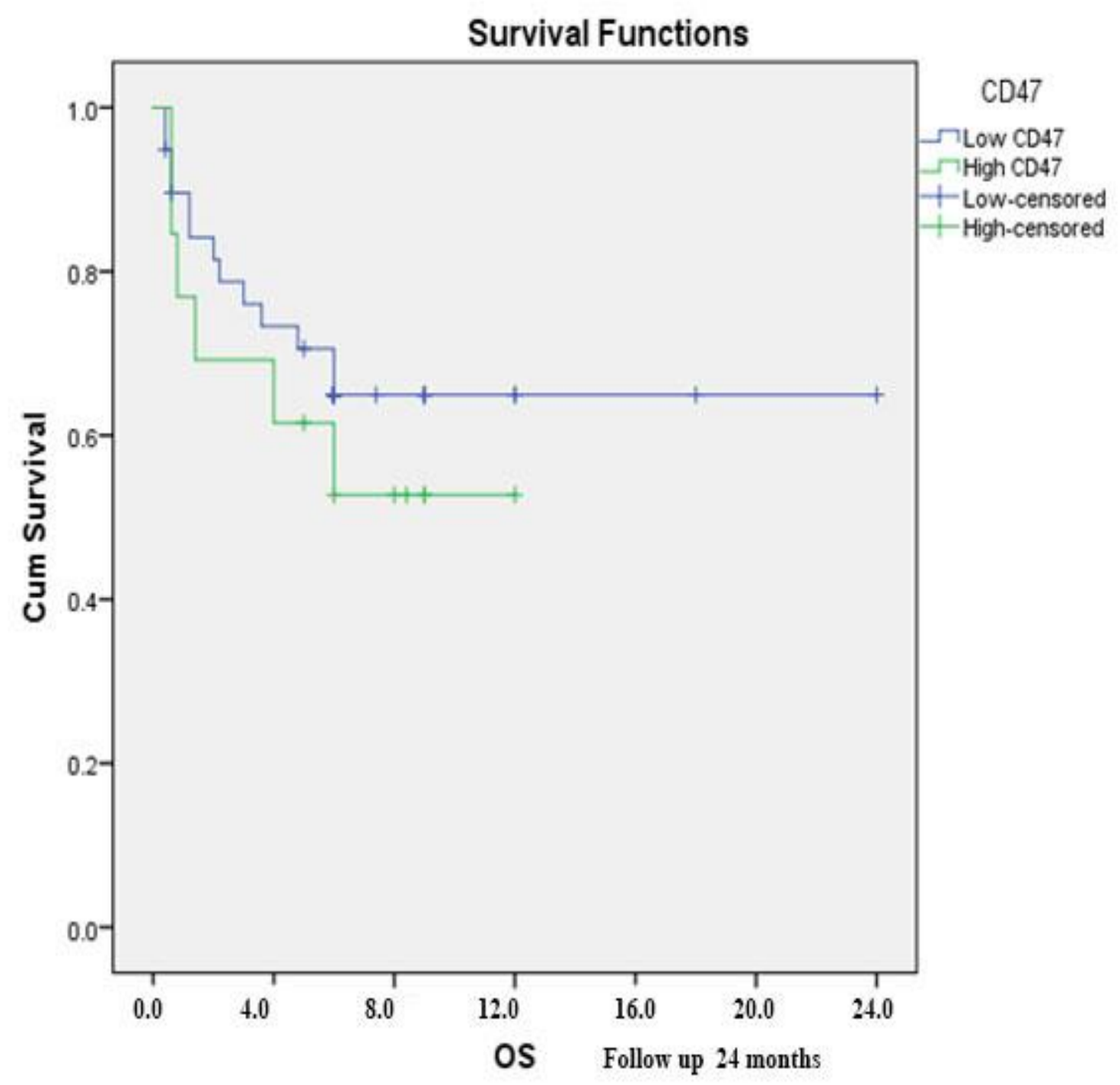

\section{DISCUSSION}

CD47, a checkpoint receptor, and immune escape promoter, is overexpressed in cancer and thus constitutes an attractive target for immunotherapy intervention. The other side of the coin is that CD47 is a universal "self" marker in normal healthy tissue that regulates programmed cell removal through homeostatic phagocytosis. In addition, CD47 also participates in other, disparate physiological processes ranging from cardiovascular homeostasis regulation, neuronal development, bone remodeling, and adaptive immunity to stress response, stem cell renewal, cell adhesion, motility, proliferation, and survival (Mouro-Chanteloup et al., 2003). Hence, the present study aimed to Estimation of CD47 gene expression in Egyptian AML patients for evaluation of its role in the pathogenesis of the disease and as a prognostic marker related to overall survival. Although previous studies highlighted the potential importance of CD47 as a prognostic marker in AML (Jaiswal et al., 2009), although targeting 
CD47 is a specific movement mechanism and may also have broad applicability along with a range of cancers, the ubiquitous existence of CD47 gives a therapeutic project (Pietsch et al., 2017), these analyzes were focused on flow cytometric analysis. To achieve our study objective, blood samples from 55 AML patients and 21 healthy individuals as controls were subjected to a considerable magnetic selection of CD34+ leukemic cells, and then flowcytometry estimated CD47 expression on these cells. Our study findings showed that the expression of the CD47 gene in Egyptian AML patients in contrast to their role in disease pathogenesis and as a prognostic marker correlated with frequent survival. Our results were in the line of Majeti et al., (2009) who reported that CD47 was more highly expressed on AML LSC than their normal counterparts and that increased CD47 expression predicted worse overall survival in 3 independent cohorts of adult AML patients. Previously it was reported that the targeting of leukemia cells and cell lines with anti-CD47 antibodies directly induces apoptosis. Treatment of primary human B-CLL cells has been shown to induce caspase-independent cell death (Mateo et al., 1999), while several hematopoietic cell lines have been shown to induce apoptosis by a different anti-CD47 antibody (Kikuchi et al., 2004, Kikuchi et al., 2005, Uno et al., 2007). The socio-demographic including (age and sex) and clinical data were collected, in addition to laboratory investigations had been performed such as complete blood count (CBC) parameters including hemoglobin, total leucocyte count, platelet count, and Blast Count: Peripheral Blood Smears, Bone Marrow Aspiration, and Flow cytometry were obtained. In the present study, there was a significant difference $(\mathrm{P}<0.0001)$ between the studied groups regarding hemoglobin concentration, our result agreeing with FC and Shamsi, (2016), who reported that hemoglobin levels ranged between 4.3 to $12.5 \mathrm{gm} / \mathrm{dl}$. The majority of AML patients 49 (45.8\%) had $\mathrm{Hb}$ less than $8.0 \mathrm{gm} / \mathrm{dl}$. About $27 \%$ of patients had $\mathrm{Hb}$ concentration between 8 to $10 \mathrm{gm} / \mathrm{dl}$. In addition to the WBCs and PLTs count $(103 / \mu \mathrm{L})$ in AML patients and healthy were significantly different $(\mathrm{P}$ $<0.0001$ ) between two groups. Our study findings agreeing with Chang et al., (2016), who reported that $84.1 \%$ had leukocytosis, while $6.5 \%$ had Leucopenia and only 9.4 had TLC within normal limits. The White cell count was highest in patients with AML-M2 62.5 to $275 \times 109 / \mathrm{L}$, followed by AML-M0 with a range of $36-257 \times 109 / \mathrm{L}$ and, AML-M1 had a range between $36-257 \times 10^{9} / \mathrm{L}$ while the lowest count was observed M3, in the range of 18-81 and MDS 2-68×109 with an average of $41 \times 109$. The overall types of acute myeloid leukemia were more commonly seen in male patients. Age has a significant effect being more common in adults. The frequency of AML increases in adults than children in the $86 / 14 \%$ ratio. The majority of patients were anemic with a low hemoglobin concentration less than $8 \mathrm{~g} / \mathrm{dl}$ in $46 \%$ cases, leukocytosis, and thrombocytopenia. The CD47 expression differs significantly according to FAB type in AML patients. The mean of CD47 expression was increased with $\mathrm{FAB}$ type excretion, $38.6 \pm 39.5$ at M1, 51.1 \pm 34.9 at $\mathrm{M} 2,60.2 \pm 51.9$ at M3 while, those showed a decrease 33.1 \pm 22.6 with M4 and 43.2 \pm 31.4 with M5. Galli et al., (2015) reported that, $\mathrm{CD} 47$ staining on BM leukemia blasts was scored semi-quantitatively and correlated with scientific parameters and regarded prognostic elements in AML. Low (scores 0-2) and excessive (score 3) CD47 protein expression have been found in $75 \%$ and $25 \%$ of AML patients. CD47 expression considerably correlated with BM blast infiltration and peripheral blood blasts. There was an inverse correlation between concentrations of CD47 gene expression and general survival, with enhanced expression also connected with worse general survival $(\mathrm{P}<0.0001)$. Our study findings are in the line of Jaiswal et al., (2009) and Majeti et al., (2009) who conducted their work on leukemic stem cells. Analysis of AML patients disclosed a poorer 
prognosis associated with greater concentrations of CD47 expression (Tsai and Discher, 2008).

\section{Conclusion}

Our study revealed the correlation between CD47 gene expression on AML blasts in the BM and patient outcome, as measured by flow cytometry. Flow cytometry may provide a clinically useful, rapid, and effective method to aid in diagnosis in patients with AML, as well as to assess treatment progress and predict prognosis. Also, CD47 has proven to be feasible and a reliable and easy way to investigate as a potential marker in AML prognosis and over survival (OS).

\section{Acknowledgements:}

We would like to thank our pricey patients, as properly as all individuals who partly backed this piece of work.

\section{Conflicts of interest:}

Authors declared no conflicts of interest

\section{References}

Arber DA : WHO classification of acute myeloid leukemia: what the practicing clinician needs to know. Semin Hematol.2016; 56(2): 90- 95.

Chang F, Shamsi T, Waryah A: Clinical and Hematological Profile of Acute Myeloid Leukemia (AML) Patients of Sindh. J Hematol Thromb.2016; Dis 4: 239.

Clark G, Stockinger H, Balderas R, van Zelm MC, Zola H, Hart D, et al: Nomenclature of CD molecules from the Tenth Human Leucocyte Differentiation Antigen Workshop. Clin Transl Immunol. (2016) 5:e57.

Egypt cancer registry (2011): www.cancerregistry.gov.eg.

Engel P, Boumsell L, Balderas R, Bensussan A, Gattei V, Horejsi V, et al. CD nomenclature : human leukocyte differentiation antigen workshops as a driving force in immunology. J Immunol. (2015) 195:4555-63.

F C, Shamsi T. : Clinical and Hematological Profile of Acute Myeloid Leukemia (AML) Patients of Sindh. Journal of Hematology \& Thromboembolic Diseases 2016; (04).
Fagerberg L, Jonasson K, von Heijne G, Uhlen M, Berglund L: Prediction of the human membrane proteome. Proteomics. (2010) 10:11419.

Galli, S., Zlobec, I., Schürch, C., Perren, A., Ochsenbein, A. F., \& Banz, Y : CD47 protein expression in acute myeloid leukemia: A tissue microarray-based analysis. Leukemia Research,2015; 39(7), 749-756.

Jaffe E, Arber DA, Campo E, Harris NL, Quintanilla-Fend L : Hematopathology, 2nd ed. New York, NY: Elsevier; 2016.

Jaiswal S, Jamieson CH, Pang WW, Park CY, Chao MP, Majeti R, et al : CD47 isupregulated on circulating hematopoietic stem cells and leukemia cells to avoidphagocytosis. Cell 2009;138:271-85. Jiang H, Fu R, Wang H, Li L, Liu H, Shao Z : CD47 is expressed abnormally onhematopoietic cells in myelodysplastic syndrome. Leuk Res 2013;37:907-10.

Kikuchi Y, Uno S, Kinoshita Y, Yoshimura Y, Iida S, Wakahara Y, Tsuchiya M, YamadaOkabe H, Fukushima : Apoptosis inducing bivalent single-chain antibody fragments against CD47 showed antitumor potency for multiple myeloma. Leuk Res. 2005;29:445-450.

Kikuchi Y, Uno S, Yoshimura Y, Otabe K, Iida S, Oheda M, Fukushima N, Tsuchiya M : A bivalent single-chain $\mathrm{Fv}$ fragment against CD47 induces apoptosis for leukemic cells. Biochem Biophys Res Commun. 2004;315:912-918.

Majeti R, Chao MP, Alizadeh AA : CD47 is an adverse prognostic factor andtherapeutic antibody target on human acute myeloid leukemia stem cells. Cell2009;138:286-99.

Mateo V, Lagneaux L, Bron D, Biron G, Armant M, Delespesse G, Sarfati M : CD47 ligation induces caspase-independent cell death in chronic lymphocytic leukemia. Nat Med. 1999;5:12771284.

Mouro-Chanteloup, I., Delaunay, J., Gane, P., Nicolas, V., Johansen, M., Brown, E.J., Peters, L.L., Van Kim, C.L., Cartron, J.P., and Colin, Y 
: Evidence that the red cell skeleton protein 4.2 interacts with the $\mathrm{Rh}$ membrane complex member CD47. Blood .2003; 101, 338-344

Pietsch EC, Dong J, Cardoso R, Zhang X, Chin D, Hawkins R, Dinh T, Zhou M, Strake B, Feng PH, Rocca M, Santos CD, Shan X, DanetDesnoyers G, Shi F, Kaiser E, Millar HJ, Fenton S, Swanson R, Nemeth JA, Attar RM . Antileukemic activity and tolerability of anti-human CD47 monoclonal antibodies. Blood cancer journal 2017; (7): e536-e536.

Siegel RL, Miller KD, Jemal A: Cancer statistics, CA Cancer J Clin 2019;69:7-34.

Tsai RK, Discher DE : Inhibition of "self" engulfment through deactivation of myosin-II at the phagocytic synapse between human cells. J Cell Biol 2008; (180): 989-1003.

Uno S, Kinoshita Y, Azuma Y, Tsunenari T, Yoshimura Y, Iida S, Kikuchi Y, YamadaOkabe H, Fukushima N : Antitumor activity of a monoclonal antibody against CD47 in xenograft models of human leukemia. Oncol Rep. 2007;17:1189-1194. 